\title{
MALARIA PARASITAEMIA AMONG PREGNANT WOMEN IN A RURAL COMMUNITY OF EASTERN NIGERIA; NEED FOR COMBINED MEASURES
}

\author{
S. O. OGBODO, U. I. NWAGHA* A. N. C. OKAKA**, S. C. OGENYI, R. O. OKOKO \\ AND T. U. NWAGHA ${ }^{+}$
}

Department t of Medical Laboratory Sciences, College of Health Sciences, Ebonyi State University, PMB 053 Abakaliki, Nigeria, *Department of Physiology/Obstetrics and Gynaecology, College of Medicine, University of Nigeria, Enugu Campus, Nigeria. **Department of Applied Biochemistry, Nnamdi Azikiwe University, Awka, Nigeria. ${ }^{+}$Department of Haematology, College of Medicine, University of Nigeria, Enugu Campus, Enugu, Nigeria.

Tel: +2348033128233, Email: uchenna.nwagha@unn.edu.ng, uchenwagha@yahoo.com

Summary: Malaria in pregnancy is a major contributor to adverse maternal and perinatal outcome. In hyper endemic areas like ours, it is a common cause of anaemia in pregnancy in both immune and non-immune individuals and is aggravated by poor socioeconomic circumstances. The aim of this study is to assess the prevalence of asymptomatic malaria parasitaemia among pregnant women in a rural setting. 272 pregnant women, aged between 18 and 40 years in some remote rural areas of Ebonyi State, Nigeria were recruited between January 2007 and March 2008. Their blood samples were collected and examined for malaria parasite, haemoglobin and packed cell volume using standard methods. Our results showed 59.9\% prevalence of parasitaemia with the highest prevalence occurring in the first trimester (84.1\%).Among the positive cases, mild parasitaemia was recorded in $47.2 \%$ moderate parasitaemia in $37.4 \%$ while severe parasitaemia was recorded in $15.3 \%$ of cases. These differences were statistically significant $(\mathrm{P}<0.016)$. Furthermore the distribution of malaria densities in different gravidity groups showed an inverse relationship, $45.4 \%$ in primigravidae, $(31.9 \%)$ in secundigravidae and (10.4\%) among people with more than five pregnancies. These findings were statistically significant $(\mathrm{P}<0.0001)$. The prevalence of anaemia in pregnancy in this study was $62.4 \%$. Apart from the use of nets, drugs and vector control, the prevention of malaria in pregnancy in very poor socioeconomic settings should make provision for nutritional support.

Key words: Asymptomatic malaria parasitaemia, Anaemia, Pregnancy, poor socioeconomic settings.

\section{Introduction:}

Malaria infection caused by Plasmodium falciparum is a major cause of fever and anaemia in pregnant women resident in hyper endemic areas of Africa. Basically, this is as a result of reduced immunity to malaria in pregnancy (Klufio, 1992), making the pregnant women prone to severe malaria attack and subsequently anaemia. It has been shown that severe anaemia was found to be more than twice as common in women with peripheral parasitaemia as in those without parasitaemia (Shulman et al, 1992). Indeed, malaria can cause several perinatal and maternal complications including abortion, stillbirth, low birth weight and even death (Brabin, 1983, McGregor, 1987; Nyirjesy et al, 1993). Incidentally malaria infection is more rampant among the primigravidae and secundigravidae than the multigravidae (Nwagha et al, 2009). The preferential susceptibility of these sets of pregnant women may be related to some evidence that immuno-suppression associated with pregnancy, occurs more in the first than subsequent pregnancies (Riley et al, 1989; Raheed et al, 1993). Previously, the depression of cell mediated immune response to Plasmodium falciparum antigens has been implicated in this phenomenon (Riley et al, 1989). Age has also been implicated as epidemiological studies have shown that malaria in pregnancy is more prevalent in younger than older age groups (Bouyou-Akotet et al, 2003; Nwagha et al, 2009). Currently, susceptibility to Plasmodium parasitaemia has been linked to the level of antibodies to placental sequestrated parasites (Elliot et $a l, 2005)$. Indeed these parasites preferentially adhere to chondroitin sulphate-A receptors (CSA) expressed by the syncytiotrophoblasts in the placenta (Fried et al, 1998). Women in their first and second pregnancies are more susceptible as anti adhesion antibodies against CSA binding parasites develop after successive pregnancies (Duffy and Fried, 1999). The presence of parasites in peripheral blood without symptoms is common in hyper-endemic areas, and is associated with chronic anaemia and placental sequestration (Nwagha et al, 2009).

Malaria infection during pregnancy contributes significantly to anaemia in pregnancy and low birth weight babies (Deen et al, 2001). Antenatal anaemia has shown positive correlation with low birth weight (LBW) and high infant 
mortality rate (IMR). Indeed, the use of effective anti-malarial drugs during pregnancy has been found to lower the frequency of LBW and reduce IMR (Steketee et al, 1996; Verhoeff et al, 1998; Kayentoa et al, 2005).

The prevention of malaria in pregnancy includes intermittent preventive treatment (IPT), in which full dose of a drug is given at defined intervals. IPT has been shown to have the potential to provide some of the benefits of sustained prophylaxis in pregnant women, and it is a promising approach to malaria control (Kayentoa et al, 2005; Falade et al, 2007). The use of insecticide treated net (ITN) has also been advocated and has shown potential efficiency in the control of mosquito bites. However, it is certain that a pregnant woman cannot remain under the net for more than 8 hours a day; hence it does not give complete protection against malaria (Nwagha et al, 2009). Moreover sulphadoxine-pyrimethamine (SP), which has gradually replaced chloroquine (CQ) as the first line treatment for malaria in some parts of Africa, is already beginning to show reasonable failure rate (Briand et al, 2007). In a rural environment with poor nutritional support, the impact of the adverse effect of malaria and anaemia in pregnancy will be enormous, thus additional measures should be advocated. In this study we assessed the prevalence of malaria parasitaemia in pregnant women in a rural area of Ebonyi State of Nigeria and advocate for a collective approach to malaria prevention and treatment in malaria endemic areas.

\section{Materials and Methods}

\section{Study Area, Study Design and Methodology Study Area}

Ebonyi State was created in 1996 from the old Enugu and Abia States. The state shares boundaries with Cross River state in the east, Enugu state in the west, Abia state in the south and Benue state in the north. It has a land mass of about of 5932 square kilometers, and consists of 13 local government areas with a projected population of about 2.2 million out of which about $52 \%$ are females. It is considered as one of the educationally disadvantaged states in Nigeria. Ngbo community is in Ohaukwu local Government area of Ebonyi state with an estimated population of about one hundred and ninety six thousand $(196,000)$. There is no public water or light supply in this community. Source of drinking water is stream and toilet facilities are either bush or pit toilet. Major occupation is mainly subsistent farming with a few people doing petty trading. Christianity and African traditional religion form their major religious beliefs. The health centers used in this study have only one trained midwife each assisted by locally trained birth attendants. Facilities for blood banking were unavailable Subject

This is cross sectional study involving 272 pregnant women, aged between 18 and 40 years. After obtaining ethical clearance from the relevant body, apparently healthy pregnant women attending antenatal clinic, who were not on any form of malaria prophylaxis were counseled, oral informed consent obtained and were recruited by simple random sampling using a lucky dip of Yes or No. They were from the antenatal clinics of two rural health centers of Ngbo in Ohaukwu local Government area of Ebonyi State of Nigeria. Out of this number, 44 were in the first trimester, 82 in the second trimester while the remaining 146 were in the last trimester. Also, 126 of this number were either primigravidae or secundigravidae while the remaining were multigravidae.Patients that had symptoms indicating malaria, example; fever, headache, weakness, anorexia and joint/muscle pains were excluded from the study. Also excluded were subjects who had some form of antimalaria drugs in the index pregnancy and who slept in ITNs. Other exclusions include human immunodeficiency virus (HIV) positive patients, sickle cell disease, diabetes mellitus, hypertension and any other diagnosed medical condition in pregnancy. We wanted to exclude the possible effect these variables will have on the body's response to the presence of malaria parasite. All the subjects were of low socioeconomic status (subsistent farmers and petty traders).

Personal history, history of present pregnancy, past obstetric history, past medical history, family and social history and review of systems were obtained. The gestational age was assessed from the last normal menstrual period. The expected date of delivery was calculated using the Naegele's rule. This rule is a pregnancy due date calculator named after a German Obstetrician who devised the rule .It calculates approximately the Expected Date of Delivery (EDD) from the first day of the woman's Last Menstrual Period (LMP). It is done by totaling a year, deducting three months from that year and adding up seven days (Cunninghams et al, 1989). Trimester was defined as first trimester $(<14$ weeks), second (14 weeks -27 weeks) and third (> 27weeks).

Medical and obstetric examinations were done. Axillary temperature was taken to exclude fever and temperature of less than $37.5^{\circ} \mathrm{C}$ was considered as normal. The antenatal laboratory investigations, as done in our center include; Genotype, Screening for syphilis, hepatitis B and HIV, were normal. In our environment, HIV screening is done for all pregnant women.

\section{Laboratory Methods}

After cleaning the volar surface of the arm with cotton wool moistened with methylated spirit, 
Malaria parasitaemia among pregnant women

peripheral blood samples were collected in sterile containers. Thin and thick blood smears were made from each of these samples, stained with Geimsa and then examined under the microscope using $\mathrm{x} 100$ objective lens in each case. Identification of species was done using the thin blood smear. The parasite density was estimated on the thick smear under oil immersion and viewed using x100 objective lens. The determination was by counting the number of asexual forms of Plasmodium falciparum parasites against at least 100 leucocytes and 200 leucocytes for definitive count. The number of asexual parasites was calculated using this formula

Parasites/uL $=\quad$ No of asexual parasites $\mathrm{x} 8000$ leucocytes/200 leucocytes

The degree of parasitaemia was graded thus (1-999/ uL) as mild or,$+(1000-9999 / \mathrm{uL})$ as moderate or ,++ and $(>10000 / \mathrm{uL})$ as severe or +++ .

A negative result was recorded after thorough examination of 100 fields without any parasite. Quality control was ensured by using freshly reconstituted and filtered Geimsa stains. The microscopist is very experienced and spent an average of 15 minutes to one hour on each thick and thin film respectively. Comparison was made with both known positive and negative thin films. Samples were also estimated for PCV using the microhaematocrit centrifugation while hemoglobin concentration was estimated spectrophotometrically using the cyamethaemoglobin method (Chesbrough 2000). All laboratory analyses were done on the day of sample collection except microscopy. All the patients with malaria parasites and anaemia were promptly and adequately treated free of charge.

\section{Statistical analysis}

This was done using SPSS version 11 computer software. Results were presented as simple percentages. Test for significance was done using Chi square and ANOVA where applicable. $\mathrm{P}$ values $\leq 0.05$ were considered significant.

\section{Results}

Table 1 shows the prevalence of malaria parasite among number and duration of pregnancies. Out of 272 subjects studied, a total of 163 were positive showing a total prevalence of $59.9 \%$.Among a total of 124 Primigravidae, 74 tested positive; a prevalence of $59.7 \%$. Secundigravidae recorded a prevalence of $59.8 \%$, while that for multigravidae was about $60 \%$. Furthermore, malaria parasitaemia was more common in the first trimester $(84.1 \%)$, followed by the second trimester $(75.6 \%)$ and then third trimester $(43.8 \%)$. The relative distribution of malaria densities in the various trimester and gravidity groups is shown in Table 2. Among the positive cases, mild parasitaemia was recorded in $77(47.2 \%)$ moderate parasitaemia in 61 (37.4\%) while severe parasitaemia was recorded in 25 $(15.3 \%)$ of cases. These differences were statistically significant (Chi square 8.331.P=0.016). The distribution of malaria densities in different gravidity groups shows that among all positive cases, $74(45.4 \%)$ occurred in primigravidae while secundigravidae recorded 52 (31.9\%). The least occurred in people with more than five pregnancies 17 (10.4\%). These findings were statistically significant (Chi square 54.644, $\mathrm{P}<0.0001$ ). The prevalence of anaemia in pregnancy in this study was $62.4 \%$. This is based on the definition of anaemia in pregnancy in our environment which is PCV of less than 30\% (Ogunbode, 1984). However among the 163 that were positive for malaria parasite; we calculated the mean PCV and haemoglobin. This was then matched against the malaria parasite densities and different trimesters as shown in Table 3 . There were statistically decrease in the $\mathrm{PCV}$ and $\mathrm{Hb}$ as malaria density increased $(\mathrm{F}=5.468, \mathrm{P}=0.005)$.

Table 1: Prevalence of asymptomatic malaria parasite showing trimester and gravidity distribution

\begin{tabular}{cccc}
\hline Variables & $\begin{array}{c}\text { Negative } \\
\text { malaria } \\
\text { parasite } \\
(n / \%)\end{array}$ & $\begin{array}{c}\text { Positive } \\
\text { malaria } \\
\text { parasite } \\
\text { s }(n / \%)\end{array}$ & $\begin{array}{c}\text { Total } \\
(n / \%\end{array}$ \\
Trimester $(\mathrm{n}=272)$ & & & \\
\hline First $(\mathrm{n}=44)$ & 7 & 37 & 44 \\
& $(15.9)$ & $(84.1)$ & $(100)$ \\
Second $(\mathrm{n}=82)$ & 20 & 62 & 82 \\
& $(24.4)$ & $(75.6)$ & $(100)$ \\
Third(n=146) & 82 & 64 & 146 \\
& $(56.2)$ & $(43.8)$ & $(100)$ \\
Total & 109 & 163 & 272 \\
& $(40.1)$ & $(59.9)$ & $(100)$ \\
Gravidity (n=272) & & & \\
Primigravidae & 50 & 74 & 124 \\
$(\mathrm{n}=124)$ & $(40.3)$ & $(59.7)$ & $(100)$ \\
Secundigravidae & 35 & 52 & 87 \\
$(\mathrm{n}=87)$ & $(40.2)$ & $(59.8)$ & $(100)$ \\
Gravida 3 to 5 & 13 & 20 & 33 \\
$(\mathrm{n}=33)$ & $(39.9)$ & $(60.1)$ & $(100)$ \\
More than 5 & 11 & 17 & 28 \\
(n=28) & $(39.3)$ & $(60.7)$ & $(100)$ \\
Total & 109 & 163 & 272 \\
& $(40.1)$ & $(59.9)$ & $(100)$ \\
\hline & & & \\
\hline
\end{tabular}


Table 2; Malaria Parasites densities showing trimester and gravidity.

\begin{tabular}{ccccc}
\hline Variable & $\begin{array}{c}\text { Mild } \\
(N \%)\end{array}$ & $\begin{array}{c}\text { Moderate } \\
(N \%)\end{array}$ & $\begin{array}{c}\text { Severe } \\
(N \%)\end{array}$ & $\begin{array}{c}\text { Total } \\
(N \%)\end{array}$ \\
\hline Gravidity & & & & \\
Primigravidae & 35 & 27 & 12 & 74 \\
& $(21.5)$ & $(16.6)$ & $(7.4)$ & $(45.4)$ \\
Secundigravidae & 20 & 24 & 8 & 52 \\
& $(12.3)$ & $(14.7)$ & $(4.9)$ & $(31.9)$ \\
Gravidae 3-5 & 13 & 4 & 3 & 20 \\
& $(8.0)$ & $(2.5)$ & $(1.8)$ & $(12.3)$ \\
More than 5 & 9 & 6 & 2 & 17 \\
& $(5.5)$ & $(3.7)$ & $(1.2)$ & $(10.4)$ \\
Total & 77 & 61 & 25 & 163 \\
& $(47.2)$ & $(37.4)$ & $(15.3)$ & $(100)$ \\
Trimester & & & & \\
& & & & \\
$1^{\text {st }}$ Trimester & 11 & 17 & 7 & 35 \\
& $(6.7)$ & $(10.4)$ & $(4.3)$ & $(21.5)$ \\
$2^{\text {nd }}$ Trimester & 15 & 33 & 14 & 62 \\
& $(9.2)$ & $(20.2)$ & $(8.6)$ & $(38)$ \\
$3^{\text {rd }}$ Trimester & 51 & 11 & 4 & 66 \\
& $(31.3)$ & $(6.7)$ & $(2.5)$ & $(40.5)$ \\
Total & 77 & 61 & 25 & 163 \\
& $(47.2)$ & $(37.4)$ & $(15.3)$ & $(100)$ \\
\hline
\end{tabular}

Table 3: Mean hemoglobin and PCV showing trimesters and malaria densities distribution.

\begin{tabular}{lll}
\hline $\begin{array}{l}\text { Variable } \\
(n=163)\end{array}$ & $\begin{array}{c}P C V \\
(\%)\end{array}$ & $\begin{array}{l}\text { Hemoglobin } \\
(\mathrm{g} \%)\end{array}$ \\
$\begin{array}{l}\text { Parasitemia } \\
\text { Mild(n=77) }\end{array}$ & $28.4 \pm 3.2$ & $9.6 \pm 1.8$ \\
Moderate(n=61) & $27.8 \pm 4.5$ & $9.5 \pm 1.2$ \\
Severe $(\mathrm{n}=25)$ & $26.9 \pm 4.0$ & $9.3 \pm 1.1$ \\
Trimester & & \\
First $(\mathrm{n}=35)$ & $27.8 \pm 4.6$ & $9.5 \pm 1.1$ \\
Second $(\mathrm{n}=62)$ & $26.9 \pm 2.6$ & $9.4 \pm 1.3$ \\
Third $(\mathrm{n}=66)$ & $26.7 \pm 2.6$ & $9.4 \pm 1.3$ \\
\hline
\end{tabular}

\section{Discussion}

A prevalence of $59.9 \%$ of malaria parasitaemia obtained from our study is comparable to previous work done in other areas; $57 \%$ in Libreville, Gabon (Bouyou-Akotet et al, 2003), 63.5\% in Awka, Nigeria in 2003 (Chukwurah et al, 2003) and 58.4\% in Enugu (Nwagha et al, 2009). Contrary to findings from other studies (Nair et al, 1993; Rogerson et al, 2000; Anorlu et al, 2001; Nwagha et al, 2009), we found no significant changes in prevalence among parity groups. This may be unrelated to the comparatively small number of subjects recruited as parity increased. However when we pooled all the positive cases, it became obvious that susceptibility was more in primigravidae. Furthermore, asymptomatic malaria parasitaemia occurred more in the first and second trimesters than third trimester. This is similar to other studies which showed that susceptibility is more marked in the second trimester than during the third trimester (Brabin, 1983; Nwagha et al, 2009). The prevalence of anaemia in pregnant Nigerian women in this study was $62.4 \%$ using our local standard (Ogunbode, 1984). Other studies also recorded high prevalence rates (BouyouAkotet et al, 2003; Brabin et al, 2004; Nwagha et al, 2009,). Furthermore, PCV and $\mathrm{Hb}$ showed a significant decrease with increasing parasite density. This is understandable as increasing parasite density ultimately leads to increase in red cell breakdown and consequently anaemia. This is aggravated by the poor socio-economic background of the patients since they are predominantly subsistent farmers. This situation calls for proper evaluation of the nutritional status of our rural pregnant women so as to assist pregnancy care givers double their efforts in malaria prevention.

ITN, IPT, integrated vector control and nutritional support as well as health education should be used concurrently in the prevention of the adverse effect of malaria in pregnancy. Indeed IPT has been shown to reduce maternal peripheral parasitaemia (Van Ejik et al, 2002), placental parasitization (Rogerson et al, 2000; Deen et al, 2001; Van Ejik et al, 2002), low birth weight (Verhoeff, 1998; Rogerson, 2000) and maternal and neonatal anaemia (Steketee et al, 1996). Indeed, the use of IPT is also indispensable as frequency of fever has not correlated well with incidence and density of malaria. It has been shown that $24.4 \%$ of parasitaemic and $25.4 \%$ aparasitaemic pregnant women had fever before their first antenatal clinic visits, giving sensitivity and specificity of fever to identify parasitaemia as $24 \%$ and $71 \%$ respectively (Steketee et al, 1996).

This prospective study was successfully completed in a local community with a difficult socio-topographic environment, irrespective of the usual difficulties encountered during community auditing in Nigeria. However, it would have been more appropriate if we had followed up these patients until delivery to enable us assess the impact of asymptomatic parasitaemia on fetomaternal outcome. This will be addressed in future studies.

This study illustrates a high prevalence of asymptomatic plasmodium parasitaemia and anaemia in pregnant rural Nigerian women. Apart from IPT and ITN, efforts should be made to incorporate other vector control measures in the context of integrated vector control. The rural areas will benefit from efforts at larva control and reduction of breeding sites like bushes near living homes. Concerted efforts to reduce poverty, improve nutrition, housing and electricity in the rural areas of Nigeria will invariably reduce the malaria burden. This will go a long way in reducing maternal and perinatal morbidity and mortality. 
Malaria parasitaemia among pregnant women

\section{Acknowledgements}

We are immensely grateful to the Chairman of Ohaukwu LGA in Ebonyi state for providing logistic support, transport, feeding and accommodation for members of our team. We also wish to thank the nurses and administrative staff at Ngbo.

\section{References}

Anorlu, R. I., Odum, C. U. and Essien, E. E. (2001). Asymptomatic malaria parasitaemia in pregnant women at booking in a primary health care facility in a peri-urban community in Lagos Nigeria. Afr. J. Med. Med. Sci. 30: $39-41$.

Brabin, B. J. (1983). An analysis of malaria in pregnancy in Africa. Bull World Health Org. 61:1005-1016.

.Brabin, B. J., Prinsen-Geerligs, P. D., Verhoeff, F. H., Fletcher, K. A., Chimsuku, L. H., Ngwira, B. M. et al. (2004). Haematological Profiles of the people of rural Southern Malawi; an overview. Ann. Trop. Med. Parasitol. 98(1):71-83.

Briand, V., Cottrell, G., Massougbodji, A. and Cot, M. (2007) .Intermittent preventive treatment for the prevention of malaria during pregnancy in high transmission areas. Malaria J. 6:160.

Bouyou-Akotet, M. K., Lonete-Collard, D. E., Mabika-Manfoumbi, M., Kendjo, E., Matsiegui, P. B., Mavoungou, E. et al. (2003). Prevalence of Plasmodium falciparum infection in pregnant women in Gabon. Malaria J. 2: 18 .

Chesbrough, M. (2000). Haematological tests. In: District Laboratory Practice in Tropical Countries (Part 2). Cambridge University Press, pp. 267-347.

Chukwura, E. I., Okpala, E. E, and Ani, I. Q. (2003). The prevalence of malaria parasites in pregnant women and other patients in Awka Urban, Anambra State. J. Biomedical Invest. 1:48-52.

Cunningham, F. G., MacDonald, P. C. and Gant, N. F. (1989). Williams Obstetrics. $18^{\text {th }}$ ed. Norwalk, Connecticut: Appleton and Lange, $\mathrm{p}$ 258.

Deen, J. L., Von Seidlein, L., Pinder, M., Walraven, G. E. E. and Greenwood, B. M. (2001). The safety of the combination artesunate and pyrimethamine-sulfadoxine given during pregnancy. Trans. Roy. Soc. Trop. Med. Hyg. 95(4): 424-428.

Duffy, P. E. and Fried, M. (1999). Malaria during pregnancy; parasites, antibodies and chondroitin sulphate- A. Biochem Soc Trans. 27: 478-482.

Elliott, S. R., Brennan, A. K., Beeson, J. G., Tadesse, E., Molyneux, M. E., Brown, G. V. et al (2005). Placental malaria induces variant antibody of the cytophylic subtype immunoglobulin $\mathrm{G}_{1}\left(\operatorname{IgG}_{1}\right)$ and $\operatorname{IgG}_{3}$ that correlate with adhesion inhibitory activity. Infection and Immunity 73:5903-5907.

Falade, C., Yusuf, B., Fadero, F., Mokuolu, O., Hamer, D. and Salako, L. (2007). Intermittent preventive treatment with sulfadoxinepyrimethamine is effective in preventing maternal and placental malaria in Ibadan, south-western Nigeria. Malaria J. 6:88.

Fried, M., Nosten, F., Brockman, A., Brabin, B. J. and Duffy, P. E. (1998). Maternal antibodies block malaria. Nature. 395: 851-852.

Kayentao, K., Kodio, M., Newman, R. D., Maiga, H., Doumtabe, D., Ongoiba, A. et al. (2005). Comparison of intermittent preventive treatment with chemoprophylaxis for the prevention of malaria during pregnancy in Mali. J. Infect. Dis. 19(1): 109-116.

Klufio CA (1992). Malaria in pregnancy. PNG Med J. 35(4): 249-257.

McGregor, I. A. (1987). Thoughts on malaria in pregnancy. Parasitologia 29: 153-163.

Nair, L. S. and Nair, A. S. (1993). Effects of malaria infection on pregnancy. Indian $J$. Malaria 30: 207-214.

Nwagha, U. I,, Ugwu, V. O,, Nwagha, T. U. and Anyaehie, U. S. B. (2009). Asymptomatic Plasmodium parasitaemia in pregnant Nigerian women: almost a decade after Roll Back Malaria. Trans. Roy. Soc. Trop. Med. Hyg. 103:16-20.

Nyirjesy, P., Kavasya, T., Axelrod, P. and Fischer, P. R. (1993). Malaria during pregnancy: neonatal morbidity and mortality and the efficacy of chloroquine chemoprophylaxis. Clin. Infect. Dis. 16(1): 127-132.

Ogunbode, O. (1984). Management of anaemia in pregnancy. Niger. Med. Pract. 8: 105-107.

Rasheed, F. N., Bulmer, J. N., Dunn, D. T., Menendex, C., Jawla, M. F. B., Jepson, A. et al (1993). Suppressed peripheral blood and placental blood lymphoproliferative responses in first pregnancies: relevance to malaria. Am. J. Trop. Med. Hyg. 48: 154-160.

Riley, E. M., Schneider, G., Sambou, I. and Greenwood, B. M. (1989). Suppression of cell mediated immune responses to malaria antigens in pregnant Gambian women. Am. J. Trop. Med. Hyg. 40:141-144.

Rogerson, S. J., Chaluluka, E., Kanjala, M., Mkundika, P., Mhango, C. G. and Molyneux, M. E. (2000). Intermittent sulphadoxinepyrimethamine in pregnancy: effectiveness against malaria morbidity in Blantre, Malawi 1997-1999. Trans. Roy. Soc. Trop. Med. Hyg. 94: 549-553.

Shulman, C. E., Graham, W. J., Jilo, H., Lowe, B. S., New, L., Obiero, J. et al (1996). Malaria is 
an important cause of anemia in primigravidae: evidence from a district hospital in coastal Kenya. Trans. Roy. Soc. Trop. Med. Hyg. 90(5): 535-539.

Steketee, R. W., Wirima, J. J. and Campbell, C. C. (1996). Developing effective strategies for malaria prevention programs for pregnant African women. Am. J. Trop. Med. Hyg. 55(1): 95-100.

Verhoeff, F. H., Brabin, B. J., Chimsuku, L., Kazember, P., Russell, W. B. and Broadhead, R. L. (1998). An evaluation of the effects on intermittent sulfadoxine-pyrimethamine treatment in pregnancy on parasite clearance and risk of low birth weight in rural Malawi. Am. J. Trop. Med. Parasitol. 92(2): 141-50.

Van Ejik, A. M., Ayisi, J. G., Ter Kulie, F. O., Misore, A. O., Otieno, J. A., Rosen, D. H. et al (2002). Risk factors for malaria in pregnancy in an urban and peri-urban population in Western Kenya. Trans. Roy. Soc. Trop. Med. Hyg. 96(6): 586-592.

Received: July 10, 2009

Accepted: October 26, 2009 